\title{
Effect of aminophylline administration on the diagnostic yield of vasodilator myocardial perfusion imaging
}

\author{
Hussein Abu Daya, MD, ${ }^{\mathrm{a}}$ and Fadi G. Hage, MD, FACC, FASH, FASNC ${ }^{\mathrm{b}, \mathrm{c}}$ \\ ${ }^{a}$ Department of Medicine, University of Pittsburgh, Pittsburgh, PA \\ ${ }^{b}$ Division of Cardiovascular Disease, University of Alabama at Birmingham, Birmingham, AL \\ ' Section of Cardiology, Birmingham Veterans Affairs Medical Center, Birmingham, AL
}

Received May 19, 2016; accepted May 19, 2016

doi:10.1007/s12350-016-0553-9

\section{See related article, pp. $1571-1578$}

The last few decades have witnessed a steady increase in the proportion of myocardial perfusion imaging (MPI) tests that utilize pharmacologic stress instead of exercise. ${ }^{1}$ Currently regadenoson, a pyrazole derivative of adenosine selective for the $\mathrm{A}_{2 \mathrm{~A}}$ receptor, is the most commonly used vasodilator agent accounting for more than $80 \%$ of all pharmacological stress tests performed in the USA. ${ }^{2}$ The widespread utilization of regadenoson is supported by multiple factors including its similar diagnostic and prognostic performance to adenosine when used for MPI, the simpler and more rapid infusion protocol, and the better safety profile in specific patient groups. ${ }^{3-6}$ Although better tolerated by patients, regadenoson shares with adenosine similar adverse effects such as flushing, headaches, and gastrointestinal symptoms. ${ }^{3,7}$ Aminophylline, a nonselective adenosine receptor antagonist, has been available on the market for decades and used to reverse the adverse effects of dipyridamole and adenosine and more recently been shown to be safe and effective for use with regadenoson. 8,9

In this issue of the Journal, Fughhi et al. ${ }^{10}$ address the concern that use of aminophylline to ameliorate the adverse effects of regadenoson may reverse its effects on coronary vasodilation and subsequent myocardial

Reprint requests: Fadi Hage, MD, FACC, FASH, FASNC, University of Alabama at Birmingham, Lyons Harrison Research Building 306, 1900 University BLVD, Birmingham, AL 35294; fadihage@uab.edu

J Nucl Cardiol 2017;24:1579-82.

$1071-3581 / \$ 34.00$

Copyright (C) 2016 American Society of Nuclear Cardiology. hyperemia reducing the sensitivity of MPI for detecting perfusion abnormalities. The data for the current study were pooled from two double-blinded, placebo-controlled randomized clinical trials, the ASSUAGE and ASSUAGE-CKD trials, ${ }^{9,11}$ which demonstrated the effectiveness of aminophylline in attenuating the adverse effects associated with regadenoson in patients undergoing MPI. In both trials, patients were randomized to receive $75 \mathrm{mg}$ of intravenous aminophylline or placebo administered at 90 seconds after radioisotope injection ( $\sim 2$ minutes following regadenoson). The primary end point of the current report was the degree of reversibility of the perfusion defect on imaging as measured by the semi-quantitative summed difference score (SDS). The secondary end point was the presence of myocardial ischemia as defined by SDS $\geq 2$. The authors also examined the effect of aminophylline use on the prognostic value of myocardial ischemia detection by MPI for cardiac events including cardiac death, myocardial infarction (MI), and coronary revascularization over a follow-up period of $29 \pm 14$ months.

The myocardial ischemic burden (primary outcome) and the presence of myocardial ischemia (secondary outcome) on MPI were similar between the two groups. However, there was a trend towards a higher proportion of abnormal perfusion (summed stress score, SSS $\geq 4$, $34 \%$ vs $27 \%, P=.08$ ) in the placebo group that the authors attributed to the significantly higher rate of prior MI (20\% vs $13 \%, P=.03)$ in this group. To account for this imbalance, the authors performed a sensitivity analysis in patients without clinical or MPI evidence (summed rest score, SRS $\geq 4$ ) of prior MI, and demonstrated similar prevalence of myocardial ischemia and abnormal perfusion between the two groups. There was no difference in the event-free survival between the study groups after adjusting for SDS, SRS, prior MI, and left ventricular ejection fraction, and no interaction 

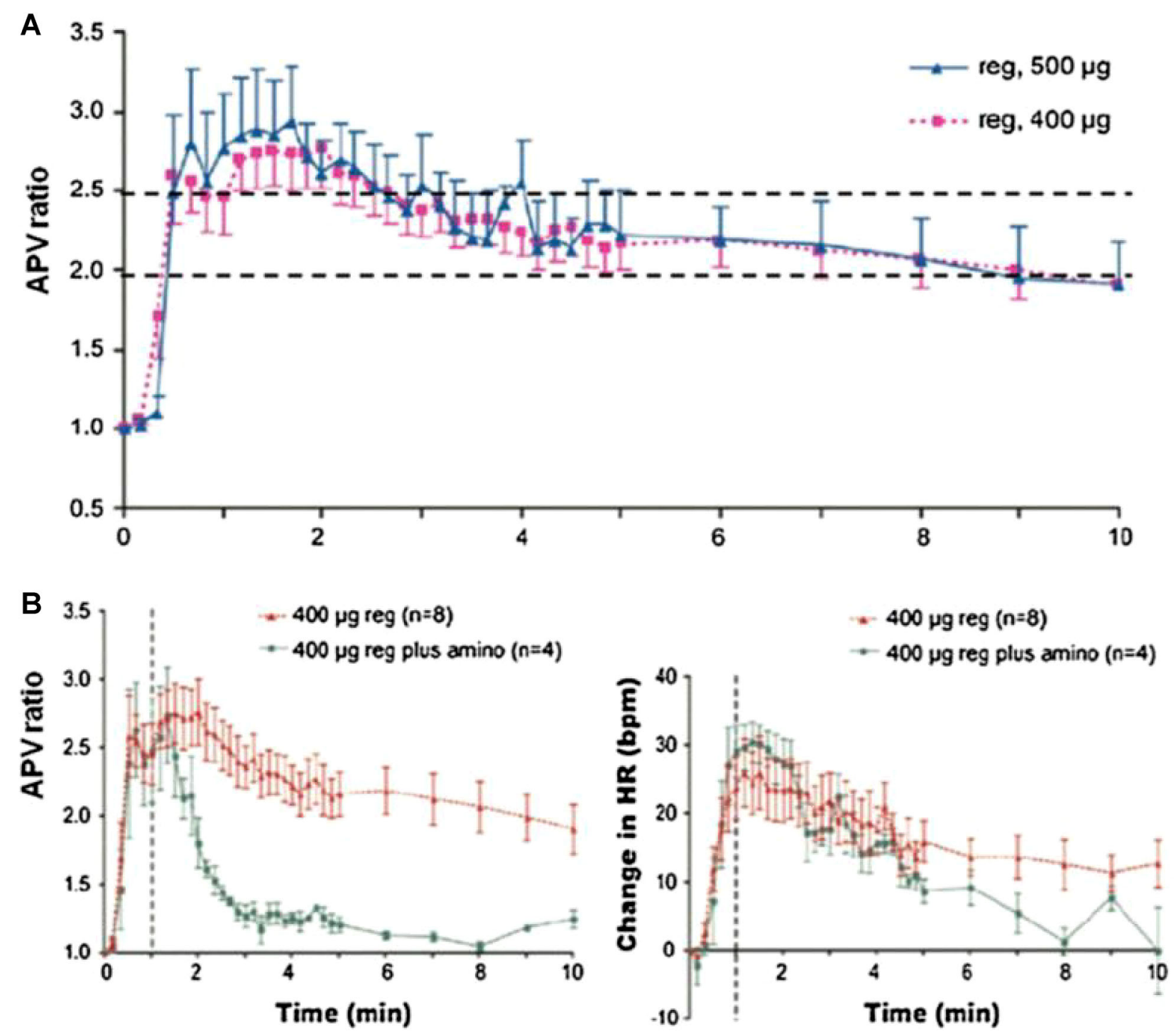

Figure 1. (A) Time dependence of 400 and $500 \mu \mathrm{g}$ of IV regadenoson bolus on average peak coronary flow velocity (APV) ratio; (B) Effects of $400 \mu \mathrm{g}$ of IV regadenoson bolus on APV ratio and heart rate before and after administration of $100 \mathrm{mg}$ of IV aminophylline (modified from Lieu et al. ${ }^{12}$ and Zoghbi et al. ${ }^{24}$ ).

between aminophylline use and SDS or myocardial ischemia ( $\operatorname{SDS} \geq 2$ ) as a determinant of cardiac events in the overall cohort and after excluding patients with prior MI. Reassuringly, there was no difference in events between the two groups in the cohort of patients with normal perfusion on imaging. The authors concluded that aminophylline administration $\sim 2$ minutes after regadenoson injection ameliorated regadenoson-induced adverse effects without a detectable effect on the diagnostic performance of MPI.

Following IV bolus administration of regadenoson, the maximal venous plasma concentration of the drug is usually reached after 1-3 minutes and myocardial blood flow (MBF) velocity increases by $>2.5$ folds for at least 2 minutes allowing for adequate radionuclide uptake which is a prerequisite for successful MPI ${ }^{12}$ (Figure $1 \mathrm{~A})$. In the study by Lieu et al., ${ }^{12}$ the peak MBF velocity $(3.1 \pm 0.5$ fold) associated with $400 \mu \mathrm{g}$ IV bolus of regadenoson was reached within 0.5-2.3 minutes with a mean of 33 seconds (range of 2040 seconds) to reach $\geq 85 \%$ of maximal flow. In addition, the increase in peak flow velocity by $>2.5$-fold was maintained for a mean of 2.3 minutes. In the same study, administration of $100 \mathrm{mg}$ IV aminophylline at 1 minute after regadenoson did not alter peak MBF increase but it did significantly abbreviate regadenoson-induced 
coronary hyperemia (Figure 1B) raising concerns that early administration of an adenosine receptor antagonist after a regadenoson bolus may attenuate MPI abnormalities. $^{12}$

In a canine model of ischemia that evaluated myocardial uptake and clearance of ${ }^{99} \mathrm{mTc}$-tetrofosmin relative to microsphere flow, Sinusas et al. ${ }^{13}$ demonstrated that ${ }^{99} \mathrm{mTc}$-tetrofosmin cleared rapidly from the blood and was retained by the myocardium whereby its uptake and clearance by ischemic and non-ischemic myocardium plateaus almost 100 seconds after its injection. Similarly, Takahashi et al. ${ }^{14}$ showed in bloodperfused rat hearts that the net tissue extraction of ${ }^{99}$ mTc-tetrofosmin plateaus within 100 seconds. ${ }^{14}$ Thus, at least theoretically, antagonism of adenosine receptors at least 100 seconds after regadenoson administration should not interfere with myocardial uptake of the tracer. Based on these data, and allowing 10 seconds for the drug to reach the coronary capillary bed, The ASSUAGE trials, on which the study by Fughhi et al. ${ }^{10}$ is based, administered aminophylline at 90 seconds after tracer administration.

It is important to interpret the results of the study by Fughhi et al. ${ }^{10}$ with caution since the findings are based on post hoc analysis of studies that were not designed or powered to address this issue. As pointed out earlier, the higher prevalence of abnormal myocardial perfusion in the placebo group is another reason to pause when interpreting the findings although the authors have attributed this to the imbalance in the distribution of patients with prior MI between the 2 randomized groups. Ultimately, the optimal study to assess the effect of aminophylline on the diagnostic performance of regadenoson MPI would be a crossover clinical trial in which patients, in addition to the rest scan, undergo two stress scans and are randomized to receive aminophylline or placebo after regadenoson administration. The proper analysis of such a study has been discussed previously. ${ }^{15}$

Caffeine, another adenosine receptor antagonist, also has the potential to oppose the effects of regadenoson. ${ }^{16}$ A recent study investigated the use of IV and oral caffeine as a potential alternative to aminophylline for the reversal of regadenoson-induced adverse effects. ${ }^{17}$ The significance of prior caffeine consumption on regadenosoninduced coronary hyperemia and the diagnostic sensitivity of MPI for detection of perfusion abnormalities have been recently debated in the Journal. ${ }^{18-22}$ Our view is that moderate caffeine consumption (i.e., $\leq 2$ cups of coffee more than 1 hour prior to presentation to the stress laboratory) does not alter coronary flow reserve to such an extent to significantly impact myocardial perfusion pattern on MPI. In line with this view, the recently released American Society of Nuclear Cardiology imaging guidelines for SPECT nuclear cardiology procedures: Stress protocols and tracers states that ingestion of caffeinated foods or beverages within the last 12 hours prior to regadenoson MPI (or other vasodilator stress agents) should be avoided but downgraded this from an absolute to a relative contraindication. ${ }^{23}$

The study by Fughhi et al. ${ }^{10}$ provides some reassurance that administration of aminophylline, when delayed by at least 2 minutes, does not substantially interfere with the effects of regadenoson on myocardial perfusion by MPI. Therefore, when significant complications are encountered as summarized in the recent guidelines, ${ }^{23}$ reversal of regadenoson should be considered without concern for altering findings on imaging. Whether reversal of regadenoson using IV aminophylline or caffeine should be undertaken on a routine basis irrespective of symptom development continues to be a matter of debate.

\section{Disclosure} USA.

Dr Hage reports grant funding from Astellas Pharma

\section{References}

1. Rozanski A, Gransar H, Hayes SW, Min J, Friedman JD, Thomson LE, et al. Temporal trends in the frequency of inducible myocardial ischemia during cardiac stress testing: 1991 to 2009. J Am Coll Cardiol 2013;61:1054-65.

2. American Society of Nuclear Cardiology/MedAxiom Nuclear Survey 2013. J Nucl Cardiol 2014;21 Suppl 1:5-88

3. Iskandrian AE, Bateman TM, Belardinelli L, Blackburn B, Cerqueira $\mathrm{MD}$, Hendel RC, et al. Adenosine versus regadenoson comparative evaluation in myocardial perfusion imaging: Results of the ADVANCE phase 3 multicenter international trial. J Nucl Cardiol 2007; 14:645-58.

4. Hage FG, Ghimire G, Lester D, McKay J, Bleich S, El-Hajj S, et al. The prognostic value of regadenoson myocardial perfusion imaging. J Nucl Cardiol 2015;22:1214-21.

5. Saab R, Hage FG. Vasodilator stress agents for myocardial perfusion imaging. J Nucl Cardiol 2016. doi:10.1007/s12350-0160408-4.

6. Hage FG. Regadenoson for myocardial perfusion imaging: Is it safe? J Nucl Cardiol 2014;21:871-6.

7. Dilsizian V, Gewirtz H, Paivanas N, Kitsiou AN, Hage FG, Crone NE, et al. Serious and potentially life threatening complications of cardiac stress testing: Physiological mechanisms and management strategies. J Nucl Cardiol 2015;22:1198-213.

8. Beller GA. Pharmacologic stress imaging. JAMA 1991;265:633-8.

9. Doukky R, Morales Demori R, Jain S, Kiriakos R, Mwansa V, Calvin JE. Attenuation of the side effect profile of regadenoson: A randomized double-blinded placebo-controlled study with aminophylline in patients undergoing myocardial perfusion imaging. "The ASSUAGE trial”, J Nucl Cardiol 2012;19:448-57.

10. Fughhi I, Campagnoli T, Ali A, Doukky R. Impact of a regimented aminophylline administration protocol on the burden of regadenosoninduced ischemia detected by SPECT myocardial perfusion imaging. J Nucl Cardiol 2016. doi:10.1007/s12350-016-0506-3. 
11. Doukky R, Rangel MO, Dick R, Wassouf M, Alqaid A, Margeta B. Attenuation of the side effect profile of regadenoson: A randomized double-blind placebo-controlled study with aminophylline in patients undergoing myocardial perfusion imaging and have severe chronic kidney disease - the ASSUAGECKD trial. Int J Cardiovasc Imaging 2013;29:1029-37.

12. Lieu HD, Shryock JC, von Mering GO, Gordi T, Blackburn B, Olmsted AW, et al. Regadenoson, a selective A2A adenosine receptor agonist, causes dose-dependent increases in coronary blood flow velocity in humans. J Nucl Cardiol 2007;14:514-20.

13. Sinusas AJ, Shi Q, Saltzberg MT, Vitols P, Jain D, Wackers FJ, et al. Technetium-99m-tetrofosmin to assess myocardial blood flow: Experimental validation in an intact canine model of ischemia. J Nucl Med 1994;35:664-71.

14. Takahashi N, Dahlberg ST, Gilmore MP, Leppo JA. Effects of acute ischemia and reperfusion on the myocardial kinetics of technetium 99m-labeled tetrofosmin and thallium-201. J Nucl Cardiol 1997;4:524-31.

15. Iskandrian AE, Hage FG, Shaw LJ, Mahmarian JJ, Berman DS. Serial myocardial perfusion imaging: Defining a significant change and targeting management decisions. JACC Cardiovasc Imaging 2014;7:79-96.

16. Hage FG, Iskandrian AE. The effect of caffeine on adenosine myocardial perfusion imaging: Time to reassess? J Nucl Cardiol 2012;19:415-9.
17. Doran JA, Sajjad W, Schneider MD, Gupta R, Mackin ML, Schwartz RG. Aminophylline and caffeine for reversal of adverse symptoms associated with regadenoson SPECT MPI. J Nucl Cardiol 2016. doi:10.1007/s12350-016-0452-0.

18. Saab R, Bajaj NS, Hage FG. Caffeine does not significantly reduce the sensitivity of vasodilator stress myocardial perfusion imaging. J Nucl Cardiol 2016;23:442-6.

19. Saab R, Bajaj NS, Hage FG. Caffeine intake and myocardial perfusion imaging. J Nucl Cardiol 2016;23:605.

20. Reyes E. Caffeine reduces the sensitivity of vasodilator MPI for the detection of myocardial ischaemia: Pro. J Nucl Cardiol 2016;23:447-53.

21. Christian TF. The judgement of the eye. J Nucl Cardiol 2016;23:454-6.

22. Reyes E. Caffeine does not significantly reduce the sensitivity of vasodilator stress MPI: Rebuttal. J Nucl Cardiol 2016;23:604.

23. Henzlova MJ, Duvall WL, Einstein AJ, Travin MI, Verberne HJ. ASNC imaging guidelines for SPECT nuclear cardiology procedures: Stress, protocols, and tracers. J Nucl Cardiol 2016;23:60639 .

24. Zoghbi GJ, Iskandrian AE. Selective adenosine agonists and myocardial perfusion imaging. J Nucl Cardiol 2012;19:126-41. 